\title{
VIOLÊNCIA DE GÊNERO NO LITORAL DO PARANÁ: DESAFIOS E POSSIBILIDADES
}

\section{GENDER VIOLENCE IN PARANÁ'S COAST: CHALLENGES AND POSSIBILITIES}

Marcos Claudio Signorelli[1]

\section{RESUMO}

O presente artigo empreende reflexão sobre desafios e possibilidades acerca da violência de gênero no litoral do estado do Paraná, uma das regiões de menor Índice de Desenvolvimento Humano (IDH) do estado. A metodologia do estudo envolveu aspectos qualitativos e quantitativos, ao combinar diferentes abordagens de pesquisa. Como principais resultados, são apontados na realidade dessa região: presença significativa de diferentes manifestações de violência de gênero, tais como violência doméstica contra mulheres e homofobia; parco acesso às políticas públicas de enfrentamento das assimetrias de gênero; e iniciativas ainda relativamente isoladas para minimização da questão, ligadas principalmente à gestão pública e instituições de ensino superior. A partir da reflexão da atual conjuntura, buscou-se ponderar sobre algumas estratégias que podem descortinar novos horizontes para o problema.

Palavras-chave: Gênero, Violência de Gênero, Violência Doméstica Contra Mulheres, Políticas públicas.

\section{ABSTRACT}

This article performs reflections about challenges and opportunities on gender violence in coast of Paraná's state. This is one of the lowest Human Development Index (HDI) areas within the state. The methodology of this study involved qualitative and quantitative aspects, combining different research approaches. The most important results for the context of this region are: significant presence of different kinds of gender based violence, such as domestic violence against women and homophobia; limited access to public policies for dealing with gender differences; and relatively isolated initiatives to minimize these issues, mainly related to municipal public administration and institutions of higher education. Based on reflections of the current situation, we tried to think about some strategies that could bring out new horizons for this issue.

Key words: Gender, Gender Violence, Domestic Violence Against Women, Public Policies.

\section{INTRODUÇÃO}

A violência vem se constituindo em objeto de diversos estudos, em distintas áreas do conhecimento. Não é desvelada como inerente à natureza humana, mas sim um fenômeno complexo e dinâmico cujo espaço de surgimento e desenvolvimento é a vida em sociedade. Diversos autores têm se debruçado sobre o estudo da violência. No Brasil, um dos importantes autores que vem se dedicando ao estudo do tema é Roberto da Matta (1982). O autor sustenta que a violência é própria da condição humana, possuindo facetas negativas e positivas e que seus referenciais variam de acordo com a sociedade em questão. $\mathrm{O}$ autor propõe que o discurso a respeito da violência seja interrogativo e relativizador ao invés de normativo e valorativo, criticando o discurso do senso comum que a coloca mais como um modo de ação do que um processo que permeia o sistema. Partindo dessa premissa, é possível observar

№: 23-24 Ano: 13 jul/ago/set/out/nov/dez 2011 
que as manifestações violentas aparecem em diferentes configurações, variando de acordo com referenciais históricos, sociais, culturais e também de gênero. A discussão sobre o conceito de violência é extensa e não poderei reproduzi-la aqui. Trata-se sobretudo de alertar, com Da Matta, para a necessidade de percebermos a violência como uma questão a ser interrogada, afastando este artigo de concepções valorativas e normativas.

Atualmente, a violência atinge homens e mulheres de diferentes maneiras e em diversas etapas da vida: desde a infância, adolescência, idade adulta até a senilidade. As diferentes manifestações de violência ocasionam, além dos transtornos a quem sofre diretamente dela, grande ônus a toda população, uma vez que grande parte de ações, políticas e recursos de um país são destinados às medidas de prevenção e contenção dessa manifestação (VILLAGÓMEZ, 2005; ADEODATO et al., 2005).

A violência está hoje entre as maiores causas de morbidade e mortalidade de muitos países do mundo, incluído nesse grupo o Brasil (WAISELFISZ, 2008). Em meio a diversas formas de violência, destacam-se a violência do trânsito, a violência institucional, a violência ligada às religiões e/ou grupos étnicos, a violência de gênero, a violência doméstica, a violência intrafamiliar, a violência urbana, entre muitas outras. Neste trabalho, será dado relevo à violência de gênero.

Oliveira (2005) relata que a violência se apresenta de forma diferente para homens e mulheres. O homem sofre a violência majoritariamente nas ruas, nos espaços públicos e em geral praticada por outro homem, majoritariamente um estranho. Enquanto isso, a mulher sofre predominantemente a violência masculina, ou seja, perpetrada por homens, dentro de casa, no espaço privado e seu agressor é com frequência o namorado, marido, companheiro ou ex-cônjuge. Nesse caso é chamada violência doméstica. Esse relato corrobora diversos outros (PINKER, 1999), merecendo destaque o trabalho desenvolvido por Lia Zanotta Machado (1998, p. 5), a qual afirma que “...mata-se e morre-se mais no masculino. No feminino morre-se um pouco menos, e mata-se muitíssimo menos". A autora estudou uma pesquisa feita pelo Movimento Nacional de Direitos Humanos, sobre notícias de homicídios em periódicos diários de 15 estados brasileiros, durante os anos de 1995 e 1996. De acordo com os registros, são homens $97,10 \%$ dos acusados e $89,70 \%$ das vítimas. Segundo a autora, a violência também tem idade construída social e culturalmente. A pesquisa revela que a faixa etária dos 18 aos 35 anos é a que mais apresenta homens assassinos e homens que perdem a vida violentamente.

Entretanto, pesquisas como essa, devem ter seus resultados analisados com cautela e de maneira contextualizada, caso contrário podem ser capazes de induzir conclusões precipitadas. Uma delas é, conforme abordado por Machado (1998), se a violência é mais comum no masculino (tanto como perpetradores quanto como vítimas), então por que se preocupar com a violência contra as mulheres?

O fato é que na pesquisa acima são contabilizados apenas os casos em que existem homicídios. Para que um caso de violência doméstica contra mulher culmine em seu assassinato, muitos outros atos violentos menores (mas não menos lesivos) já perpassaram, sendo o assassinato o ápice da demonstração da brutalidade. Ademais, a violência urbana que acontece nas ruas e em espaços públicos é muito mais visível (e visibilizada) do que a violência doméstica, que ocorre no privado dos lares. A vítima de violência doméstica nem

№: 23-24 Ano: 13 jul/ago/set/out/nov/dez 2011 $12 \quad$ Cadernos de Gênero e Tecnologia 
sempre denuncia o crime, e mesmo quando denuncia, nem sempre o crime é visto como tal pelas autoridades. O caso de violência doméstica nem sempre é investigado e os agressores nem sempre são punidos.

A violência contra mulheres que ocorre predominantemente no interior de seus lares e por isso é categorizada como doméstica, é problema presente e recorrente na maioria das sociedades. A Organização Mundial da Saúde (OMS) estima que, no mundo, uma em cada três mulheres é ou já foi vítima de violência doméstica. Diversos pesquisadores vêm estudando essa questão, em diferentes realidades e contextos. Embora de difícil quantificação em valores absolutos, algumas pesquisas, em especial aquelas de caráter multicêntrico[2], vêm relatando que esse problema é ainda mais comum nos chamados "países em desenvolvimento", estando o Brasil entre esse grupo.

Tais trabalhos evidenciam então, especificidades de gênero no complexo estudo relacionado à violência. Tais especificidades podem estar envolvidas inclusive na causa da violência, sendo, portanto, utilizado comumente o termo "violência de gênero", que é definido por Suárez e Bandeira (1999) como acontecimentos violentos abrigados nos diferentes relacionamentos de gênero, que são relacionamentos que podem pôr em interação conflituosa não apenas homem e mulher, mas também mulher e mulher ou homem e homem. A ligação entre violência e gênero é importante para indicar não somente o envolvimento de mulheres e de homens como vítimas e autores (as), mas também seu envolvimento como sujeitos, que buscam firmar mediante a violência, suas identidades masculinas ou femininas. As autoras ainda acrescentam que a violência de gênero pode ser ligada tanto a questões afetivas e emocionais - como exemplificam agressões que ocorrem entre homens e mulheres nos espaços domésticos e entre homens e homens nos espaços de lazer - como a situações calculadas e utilitárias, como é o caso de estupro de pessoas estranhas e sem vínculo afetivo.

Para melhor compreensão da seriedade da violência que recai sobre mulheres, considerada tão grave quanto a que recai sobre homens, é necessária uma compreensão de como se dão as relações de poder entre homens e mulheres. E para o entendimento dessa conjuntura é imprescindível que tomemos como referência os estudos de gênero. Joana Maria Pedro (2005) desenhou um panorama histórico da construção de distintas categorias utilizadas em estudos nesse campo, tais como: mulher, mulheres, gênero e sexo. A autora faz um diálogo entre academia, teorias e a história dos movimentos sociais de mulheres, de feministas, de gays e de lésbicas, sugerindo que gênero é uma categoria de análise, da mesma forma como quando se fala em classe, raça/etnia, geração. E complementa, argumentando que a palavra gênero passa a ser utilizada no bojo do movimento feminista nos anos oitenta, no lugar da palavra sexo, buscando reforçar a idéia de que diferenças nos comportamentos de homens e mulheres não eram dependentes do sexo como questão biológica, mas definidos pelo gênero, e ligadas à cultura. Assim, o termo gênero tem, portanto, uma trajetória que acompanha a luta por direitos humanos, por equidade e respeito.

Os estudos de gênero problematizam atitudes socialmente esperadas e aceitáveis para homens e mulheres, frutos do contexto histórico-cultural. Para Schiebinger (2001, p. 46), “...gênero denota entendimentos multidimensionais e mutáveis do que significa ser um homem ou uma mulher, no interior de um determinado ambiente social." Para a autora, o sexo em contraste, figura dentro dos estudos de gênero para designar aspectos menos maleáveis da biologia, podendo ter uma variedade de significados. Para exemplificar esse

№: 23-24 Ano: 13 jul/ago/set/out/nov/dez 2011 
postulado, ela destaca por um lado os encontros românticos altamente ritualizados; por outro lado redutivamente o intercâmbio de material genético fazendo referência à biologia de um indivíduo, onde macho é aquele que produz gametas espermatozóides e fêmea é aquela que produz óvulos.

Em 1968, Robert Stoller no livro "Sex and gender" empregou primeiramente o termo gênero, buscando distinguí-lo em relação ao sexo. Nesta obra, Stoller discutiu sobre o tratamento de pessoas consideradas intersexos e transexuais. A obra abordava intervenções cirúrgicas para adaptar a anatomia genital (considerada por ele como sexo) com sua identidade sexual escolhida (considerada como gênero). Para esse autor, o sentimento de ser mulher e o sentimento de ser homem, ou seja, a identidade de gênero era mais importante do que as características anatômicas. Neste caso, o gênero não coincidia com o sexo, pois pessoas com anatomia sexual feminina sentiam-se homens, e vice-versa.

No movimento feminista a palavra gênero também passou a fazer parte dos debates, aparecendo de maneira distinta em cada momento do feminismo. O denominado primeiro momento ou primeiro período se desenvolveu no final do século XIX e se centrou nos direitos políticos (como o direito de votar e de ser eleita), direitos sociais e econômicos (trabalho remunerado, estudo, herança). Já o segundo momento do feminismo surgiu depois da $2^{\text {a }}$ Guerra Mundial, priorizando as lutas pelo direito ao corpo, ao prazer e contra o patriarcado. Nessa fase, a categoria gênero foi incorporada como tributária das lutas do feminismo e movimento de mulheres. Essa trajetória ganhou mais visibilidade nos anos 60, principalmente com os trabalhos de Betty Friedan ("A mística feminina”) e Simone de Beauvoir ("O segundo sexo"), embora o termo gênero ainda não estivesse comumente presente na agenda de feministas. Na época era realçada a categoria mulher, usada em contraposição à palavra homem, considerada universal, pretendendo incluir todos os seres humanos.

Dessa forma, as pessoas dos movimentos feministas questionavam o fato de não se sentirem incluídas quando eram nomeadas pelo masculino, como exemplo, quando se fala em "evolução do homem", ou "o homem conquista o espaço". Apesar de mulheres também serem protagonistas em tais processos, só o homem era nomeado. Traziam também à tona reivindicações em nome da mulher e não do homem universal, tais como: o direito de ter filhos quando quiser e se quiser; a luta contra a violência doméstica; a divisão de tarefas domésticas; entre outras. Buscavam, dessa forma, legitimar uma identidade de mulher. Assim, nesse segundo período do feminismo foi comum a disseminação de grupos de reflexão compostos apenas por mulheres, que discutiam questões relacionadas às suas vidas de mulheres, tais como suas histórias de vida, preconceitos, violências, etc.

A partir dessas observações começam a emergir importantes estudos de gênero. $O$ gênero, como categoria de análise, passou a ser mais utilizado, inspirado pelo texto de Joan Wallach Scott "Gênero: uma categoria útil de análise histórica", publicado no Brasil na década de 90 . Nesse trabalho, Scott retoma a diferença entre sexo e gênero, já empregada na década de 60 por Robert Stoller. Todavia, ela o articula com a noção de poder, propondo que gênero é um elemento constitutivo de relações sociais construídas sobre as diferenças percebidas entre os sexos, sendo ele um primeiro modo de dar significado às relações de poder. Assim, de maneira distinta do que Stoller havia proposto - ou seja, de que gênero era o sexo social/cultural e sexo se referia à biologia -, para Scott, gênero é constituído por

\begin{tabular}{llll}
\hline №: 23-24 Ano: $13 \quad$ jul/ago/set/out/nov/dez 2011 14 & Cadernos de Gênero e Tecnologia
\end{tabular} 
relações sociais: estas estavam baseadas nas diferenças percebidas entre os sexos e, por sua vez, constituíam-se no interior de relações de poder.

$\mathrm{O}$ uso da categoria gênero passou a permitir que pesquisadoras e pesquisadores não só focalizassem as relações entre mulheres e homens, mas também as relações entre homens e relações entre mulheres. Além de Scott, outros autores e autoras têm trazido luzes ao debate em torno da categoria, tais como Thomas Laqueur (2001), Judith Butler (2008) e Linda Nicholson (2000).

Laqueur (2001), historiador da medicina, diferentemente de Stoller e outros, que separam sexo de gênero, ou de Scott que relacionava o gênero com as diferenças percebidas entre os sexos, afirmava que era o gênero que constituía o sexo. Junto a esse autor, outras autoras passaram a questionar a forma como o gênero estava sendo pensado em relação ao sexo, pois apesar da afirmação de que se tratavam de coisas diferentes, era sobre o sexo biológico que se estava constituindo a identidade de gênero, e no caso dos integrantes dos movimentos gays e lésbicas, estes termos não coincidiam.

Nessa perspectiva, Judith Butler (2008) questionou a categoria gênero como sendo calcada no sexo biológico, em sua obra "Problemas de gênero". A autora propõe o que se denominou "teoria performática", sendo que, de acordo com esta teoria, a performatividade do gênero é um efeito discursivo, e o sexo é um efeito do gênero. Para chegar a esta questão a autora aponta diversos questionamentos, tais como: O que é o sexo? É ele natural, anatômico, cromossômico ou hormonal? E como deve a crítica feminista avaliar os discursos científicos que alegam estabelecer tais "fatos" para nós? Teria o sexo uma história? Possuiria cada sexo uma história ou histórias diferentes? Haveria uma história de como se estabeleceu a dualidade do sexo, uma genealogia capaz de expor as opções binárias como uma construção variável? Seriam os fatos ostensivamente naturais do sexo produzidos discursivamente por vários discursos científicos a serviço de outros interesses políticos e sociais? Se o caráter imutável do sexo é contestável, talvez o próprio construto chamado sexo seja tão culturalmente construído quanto gênero. Talvez o sexo sempre tenha sido o gênero, de forma que a distinção entre sexo e gênero revela-se absolutamente nenhuma.

Butler questiona, enfim, a própria categoria gênero como interpretação cultural do sexo. E ainda acrescenta que gênero não está para cultura assim como o sexo está para natureza. Dessa forma, ela focaliza o sexo como resultado discursivo/cultural e questiona a constituição do sexo como pré-discursivo e, portanto, anterior à cultura.

Outra pesquisadora referência na área de estudos de gênero é a historiadora Linda Nicholson. Ela segue as discussões de Laqueur e Butler, lembrando que separar sexo de gênero e considerar o primeiro como essencial para a elaboração do segundo pode ser uma forma de fugir do determinismo biológico, mas pode por sua vez, constituir-se num fundamentalismo biológico. Isto porque postula uma relação mais do que acidental entre a biologia e certos aspectos de personalidade e comportamento. Ou seja, funda sobre o biológico aquilo que a cultura estabelece como personalidade e comportamento de homens e mulheres.

O maior destaque que os trabalhos de gênero trazem a este artigo são subsídios para a compreensão do gênero como categoria de análise. É deveras importante compreender sua contextualização histórica e seus desdobramentos nas relações contemporâneas. Hoje,

NNo: 23-24 Ano: 13 jul/ago/set/out/nov/dez 2011 
ao discutirem-se questões relativas à violência de gênero, que compreende entre outras, violência contra mulheres e homofobia[3], recorre-se fundamentalmente ao estudo dessa categoria de análise. É por isso que a introdução deste ensaio versa sobre a construção dessa categoria, uma vez que o intuito aqui é apresentar e refletir um pouco sobre o panorama da violência de gênero no litoral do Paraná.

\section{CENÁRIO LOCAL: LITORAL DO PARANÁ E VIOLÊNCIA DE GÊNERO}

Uma vez situada contextualização teórica deste artigo, faz-se necessário situar o leitor em nosso território de atuação. Para isso, será feita breve apresentação do campo de estudos e trabalhos: o litoral paranaense. Essa é uma das regiões menos desenvolvidas social e economicamente do estado e quiçá da região sul do Brasil. É composta por sete municípios: Antonina, Guaraqueçaba, Guaratuba, Matinhos, Morretes, Paranaguá e Pontal do Paraná. Nessa região se encontram alguns dos menores Índices de Desenvolvimento Humano (IDH) do Paraná, além de indicadores sociais e de saúde que apontam graves problemas, especialmente quando comparados ao restante do estado e até do país. São maiores nesse local os índices de HIV/AIDS, tuberculose, hanseníase, bem como as taxas de desemprego, subemprego e desigualdades sociais. Um pouco desse retrato atual se deve ao próprio processo histórico herdado do período colonial: aportava-se nessa região em busca da extração de ouro e riquezas, merecendo pouca importância quem aqui vivesse ou o futuro dessa região.

Alguns dos municípios litorâneos, como Matinhos, Guaratuba e Pontal do Paraná, possuem uma característica de "extrativismo" presente até hoje, embora com outro escopo. Atualmente, uma enxurrada de turistas vêm para essas cidades para extrair de suas belezas naturais alguns meses de férias de verão. Após se esbaldarem em orgias nababescas, deixam toneladas de lixo em seu rastro. A dinâmica sócio-econômica desses locais é inteiramente marcada pela sazonalidade. Grande parte de sua gente vive em função da temporada de verão, inclusive sobrevivendo à custa da reciclagem do lixo deixado pela horda que aqui aporta anualmente. A orla marítima é formada por praias densamente disputadas durante o verão. Durante esse período do ano há geração de trabalho e de renda, entretanto, com o fim da temporada, os turistas se vão, os recursos tornam-se escassos e grande parte da população permanece à margem, sem trabalho, ociosa e sem outras fontes de renda.

Outros municípios da região, como Paranaguá e Antonina, vêem suas vidas sócioeconômicas orbitando em torno de seus respectivos portos. Esses portos geram expressiva quantidade de riquezas, entretanto, para muito poucos. E ao mesmo tempo, ascendem sérios problemas para muitos, tais como prostituição, tráfico de drogas, contrabando, proliferação de doenças, e isso sem mencionar os prejuízos ambientais. Já Morretes e Guaraqueçaba são municípios marcados pela ruralidade. Grande parte da população vive da agricultura, da pecuária, da pesca e do extrativismo. O turismo nesses locais é incipiente, se destacando o crescente apelo ao ecoturismo.

Frente a todo esse cenário já se pode imaginar como se dão as relações e interações

№: 23-24 Ano: 13 jul/ago/set/out/nov/dez 2011 $16 \quad$ Cadernos de Gênero e Tecnologia 
entre os sujeitos que habitam esse território. Assim como acontece em outras regiões do interior do Brasil, marcadas por conjunturas semelhantes, emergem sérios problemas de iniqüidades de gênero. As relações de gênero marcadamente assimétricas, com valência negativa para o feminino estão intimamente associadas a uma cultura patriarcal. Como consequiências dessa cultura, temos, entre outras manifestações, a violência de gênero. E esse é um aspecto importante de nosso campo de estudos nessa região. Pesquisamos, tentamos compreender, buscamos propor e implementar estratégias no sentido de minimizar aspectos relacionados a esse tipo de violência.

Para cumprir os objetivos supracitados, vem sendo utilizada nos últimos quatro anos uma abordagem por meio de estratégias metodológicas qualitativas e quantitativas, usadas de maneira combinadas e complementares uma à outra. A primeira etapa dos trabalhos, denominada etapa de mapeamento, com intuito de mapear questões ligadas à violência de gênero na região, teve um caráter predominantemente (embora não exclusivamente) quantitativo. Foram aplicados de maneira anônima formulários de investigação a diferentes atores sociais da região, em duas frentes distintas ou subcategorias da violência de gênero: a violência doméstica contra mulheres e a violência contra homossexuais e homofobia. Foram investigados também dois grupos distintos de indivíduos, com relação às duas referidas frentes. Com relação ao eixo violência doméstica contra mulheres, foi pesquisada a comunidade universitária de uma universidade pública da região, composta por estudantes, professores e funcionários da instituição, que residem nos municípios em tela. A comunidade universitária foi investigada a respeito de representações acerca da violência doméstica contra mulheres, tais como: o que consideram como sendo violência doméstica contra mulheres; se são vítimas e/ou autores (as); se conhecem vítimas e locais de atendimento especializado na região; entre outros aspectos. Já em relação à outra frente, a violência contra homossexuais, foram aplicados formulários à comunidade escolar (professores, diretores, funcionários, mas não estudantes) da rede pública municipal de Matinhos, que compreende o ensino fundamental ( $1^{\mathrm{a}}$ à $4^{\mathrm{a}}$ série) e a educação infantil (pré-escolar). A pesquisa buscou identificar situações observadas pela comunidade escolar a respeito da homossexualidade no ambiente escolar e seus desdobramentos, bem como situações de homofobia nas escolas.

A violência de gênero relacionada à homossexualidade foi investigada durante a realização de um projeto[4] denominado "Refletindo Gênero na Escola: a importância de repensar conceitos e preconceitos", durante o ano de 2007, contando com a participação de cerca de 120 participantes. Antes do início das atividades do projeto, as participantes (professoras, diretoras, e funcionárias, majoritariamente mulheres, da rede municipal de Matinhos) eram convidadas a participar de uma pesquisa anônima, com objetivo de mapear quantitativamente situações relacionadas ao tema. $\mathrm{O}$ instrumento utilizado continha perguntas objetivas, e após ser respondido era depositado em uma urna, sendo ao final, contabilizados os resultados. Tal instrumento revelou, entre outros aspectos, que a maioria das participantes (54\%) já teve contato no seu cotidiano de atuação no ambiente escolar, com estudante(s) considerado(s) por elas como tendo orientação sexual diferente da heterossexual, embora dessas, a maioria (64\%) considera tal situação rara.

Quando indagadas se sentiam seguras para tratar da situação (homossexualidade na escola), cerca de metade do grupo pesquisado admitiu ter dificuldades para lidar com tal circunstância. Algumas relataram conversar com o (a) estudante, enquanto outras chamaram

№: 23-24 Ano: 13 jul/ago/set/out/nov/dez 2011 
os pais. Apenas $6 \%$ referiram encaminhar à orientação educacional, mas o dado mais surpreendente é que cerca de $40 \%$ das pesquisadas "não tomam atitudes", ou seja, encaram normalmente a situação. $\mathrm{O}$ fato de tomar uma atitude não é aqui colocado nem como algo positivo nem como algo negativo. Muitas vezes tomar atitudes pode ser interessante para o (a) estudante que enfrenta problemas na escola oriundos dessa situação, especialmente quando encaminhado (a) à orientação educacional ou psicológica especializada. Em outras circunstâncias, tomar atitudes pode causar alardes e levar a uma excessiva exposição desse (a) estudante, dependendo da maneira como o caso é conduzido internamente na escola ou talvez até externamente. Assim, com base nessas respostas, sabíamos que esse era um ponto nevrálgico, que trazia angústias e incertezas aos membros da comunidade escolar, e que mereceria ser abordado ao longo das oficinas subsequentes previstas no projeto.

Em relação a situações de homofobia na escola, cerca de 54\% das participantes relataram já ter presenciado casos de piadinhas, chacotas ou comentários debochados envolvendo a orientação sexual dos(as) estudantes. Destes, dois tipos de encaminhamentos se destacam em proporção quase igual (cerca de $40 \%$ cada): um grupo referiu ficar preocupado com o ocorrido e ter ido conversar com os (as) estudantes envolvidos (as), enquanto outro grupo relatou não ter feito nenhum comentário, não ter reagido. Aqui novamente realçamos o fato de que quase a metade da comunidade escolar que presenciou situações de discriminação na escola tem uma posição extremamente passiva, e por que não dizer, neste caso, até conivente com a situação? $\mathrm{O}$ fato é que muitos realmente não sabiam quais posições deveriam adotar ou quais encaminhamentos tomar. E esse foi um dos aspectos discutidos de maneira intensa e extensa, durante as oficinas que se sucederam.

E para finalizar esse mapeamento, foi incluído no instrumento três figuras com cenas de beijos homossexuais, uma com dois homens e outras duas figuras com duas mulheres se beijando. Perguntamos qual a opinião delas ao se deparar com situações como essas. A maioria (34\%) assinalou "encarar normalmente", seguido de $19 \%$ que "aceitam, concordam e apóiam". Cerca de $12 \%$ das entrevistadas "acham diferente", enquanto algumas, mesmo que minoritariamente, escolheram respostas como: "acho anormal"; "sinto pena"; "sinto nojo" ou ainda "acho que isso é doença, um desvio", sendo esta última relatada por apenas uma pessoa. Felizmente, uma das alternativas não foi citada: "sinto raiva".

De acordo com o Programa Brasil Sem Homofobia (2004) a violência contra homossexuais - e mais especialmente contra travestis e transgêneros - que pode culminar com a letalidade, é, sem dúvida, uma das faces mais trágicas da discriminação por orientação sexual no Brasil. Tal violência tem sido denunciada com bastante veemência pelo Movimento LGBT, por pesquisadores e pesquisadoras de diferentes universidades brasileiras e pelas organizações da sociedade civil, que têm procurado produzir dados de qualidade sobre essa situação. Com base em uma série de levantamentos feitos a partir de notícias sobre a violência contra homossexuais publicadas em jornais brasileiros, os dados divulgados pelo movimento homossexual são alarmantes, revelando que nos últimos anos centenas de gays, travestis e lésbicas foram assassinados no país. O Grupo Gay da Bahia (GGB) contabilizou que, para o ano de 2004, a cada 2 dias, um homossexual foi morto no Brasil, pelo simples fato de ser homossexual. Entretanto, para além da situação extrema do assassinato, muitas outras formas de violência vêm sendo apontadas, envolvendo familiares, vizinhos, colegas de trabalho ou de instituições públicas como a escola, as forças armadas, a justiça ou a polícia. Pesquisas recentes sobre a violência que atinge homossexuais dão uma idéia mais precisa sobre as

\begin{tabular}{llll}
\hline №: 23-24 Ano: $13 \quad$ jul/ago/set/out/nov/dez 2011 18 & Cadernos de Gênero e Tecnologia
\end{tabular} 
dinâmicas mais silenciosas e cotidianas da homofobia, que englobam a humilhação, a ofensa e a extorsão. Nesse campo merece relevo a pesquisa desenvolvida por Abramovay et al. (2004) a respeito da homofobia na escola. As autoras apontam que em algumas capitais do país quase metade dos pais de alunos do ensino fundamental e médio não gostariam que houvessem homossexuais nas classes de seus filhos, e ainda, que atos homofóbicos como bater em homossexuais, são ações consideradas menos violentas do que andar armado ou fazer uso de drogas.

Assim, os elementos investigados nesse mapeamento forneceram importantes subsídios para o direcionamento das atividades nos encontros subsequentes, realizados durante as oficinas de sensibilização do referido projeto. Já havia um repertório de temas pré-estabelecidos, mas com as observações dessa pesquisa foi possível adaptar alguns dos temas abordados nos módulos, frente às necessidades levantadas. Todos os conteúdos foram trabalhados sob a modalidade de oficinas, com a participação ativa dos cursistas. As atividades foram conduzidas de maneira dinâmica, alternando-se as estratégias metodológicas entre projeções, exposições dialogadas, discussões, exibições de vídeos, exposição de arte, fotografias, atividades em grupo, músicas, elaboração de cartazes e atividades de artes visuais, entre outras.

Durante as oficinas, uma questão significativa e recorrente que emergiu em muitas discussões nos diferentes grupos foi a respeito de outras manifestações de violências de gênero, em especial a violência contra mulheres, que parecia bastante presente na realidade regional. Hoje se sabe que uma das principais causas da violência praticada contra mulheres é a desigualdade causada pelas relações de gênero tradicionais. As assimetrias de gênero se desenvolveram com a história da humanidade. Diversos estudos de gênero vêm sendo desenvolvidos nos últimos anos, promovendo reflexões sobre as relações que se estabelecem entre homens e mulheres, entre homens, e entre mulheres. (BOURDIEU, 1999; SCOTT, 1986; LOURO, 2000; SAFFIOTI, 2005; BUTLER, 2008). Esses estudos revelam (e problematizam) o fato de vivermos em uma sociedade predominantemente machista, heterossexual normativa e assimétrica, que tem como uma de suas resultantes, a produção de violência tanto contra as mulheres quanto contra homossexuais.

Entretanto, ao se tentar buscar dados quantitativos a respeito da violência contra mulheres na região em tela, observou-se que não havia nenhuma sistemática de registros ou notificação de casos em nenhum dos municípios. A região, apesar de contar com uma população em torno de 300 mil habitantes, mas que ultrapassa a casa de 1 milhão nos meses de verão, também não dispõe de Delegacia Especializada de Atendimento à Mulher (DEAM), o que dificulta a quantificação dos casos. E a isso se soma também o fato de que esse é um dado de difícil quantificação, pois envolve diversos aspectos subjetivos e pessoais. Nesse sentido, buscando mapear o problema nessa realidade, realizou-se uma pesquisa quantitativa a respeito da violência doméstica contra mulheres, com intuito de verificar, além de número de ocorrências, algumas representações acerca do tema na realidade dessa região. $\mathrm{O}$ instrumento foi construído por um grupo de um projeto[5], com base em outras pesquisas realizadas previamente pelo Instituto Brasileiro de Geografia e Estatística (IBGE), Instituto Patrícia Galvão (JORDÃO, 2006), somados a alguns anseios específicos da equipe. E para tentar conseguir uma amostra significativa, e que também refletisse o aspecto regional, foi aplicado à comunidade universitária de uma universidade regional, composta por estudantes, professores(as) e funcionários(as) oriundos(as) dos sete municípios da região. Assim, seria

№: 23-24 Ano: 13 jul/ago/set/out/nov/dez 2011 
possível retratar não só o estado da arte do município de Matinhos, mas sim de toda região.

A pesquisa foi realizada no primeiro semestre de 2008, durante dois dias consecutivos. As perguntas eram objetivas e o formulário era anônimo. As únicas identificações foram o vínculo com a universidade - docente, discente ou funcionário (a) - e se estudante, à qual curso pertencia. Foi tomado o cuidado também de garantir privacidade no momento do preenchimento do formulário, pois haviam perguntas como por exemplo, "se já foi vítima de violência doméstica" ou "se já praticou atos de violência doméstica contra mulheres". Para isso foi montada uma sala de aplicação, com biombos individuais de preenchimento e urnas para depósito das respostas. Todos os professores e funcionários da instituição foram avisados previamente das datas de realização da pesquisa, e não somente para colaborar na liberação das turmas para participação na pesquisa, mas para respondê-la também. Foram acionadas todas as turmas do campus, sendo chamada uma de cada vez, para evitar aglomerações e garantir a privacidade dos informantes.

Ao final, foram contabilizados 364 formulários, o que é considerado um universo significativo do campus, pois ultrapassava a metade da comunidade universitária total daquela época[6]. A faixa etária predominante foi dos 17 aos 30 anos, sendo que quase dois terços das pessoas que responderam eram mulheres e $47 \%$ dos participantes se declararam vivendo em estado de conjugalidade, ou seja, possuíam cônjuge, namorado (a), parceiro (a) ou relacionamento estável com outra pessoa.

A maioria absoluta (98\%) declarou saber o que é violência doméstica contra mulheres, embora $30 \%$ revelaram nunca ter visto ou ouvido campanhas sobre o assunto. Cerca de $82 \%$ acreditam que o companheiro ou a companheira são os principais responsáveis pela violência doméstica contra mulheres, seguidos de cerca de $10 \%$ que responderam ser outros familiares os responsáveis. Um dado revelador foi que cerca de $10 \%$ afirmaram que existem situações que justificam a agressão do (a) companheiro (a) à mulher. Esse é um dado que chamou muito a atenção, especialmente pelo fato de inclusive mulheres pensarem dessa maneira, pois endossaram essa afirmação.

Essa questão traz uma reflexão sobre a questão cultural em torno da problemática, que tem suas raízes numa cultura baseada no patriarcado[7]. O patriarcado tem origem na figura do patriarca, que surgiu na Roma antiga, sendo que este tinha direito de vida e de morte sobre sua esposa. Por muito tempo a cultura patriarcal vem mantendo sua hegemonia na sociedade. Segundo essa cultura, a mulher deveria manter-se submissa ao homem, sendo atribuído a ele o direito de posse de sua[8] esposa, inclusive justificando a violência que é praticada contra ela. Diversos autores e autoras têm se debruçado sobre o estudo do patriarcado, merecendo destaque Heleieth Saffioti e Lia Zanotta Machado.

Em relação aos motivos que levam o companheiro ou a companheira a cometer atos de violência doméstica contra a mulher, a pesquisa revelou que o alcoolismo (bebida) foi o aspecto mais relatado, por mais de $58 \%$ dos participantes. Outro aspecto bastante enunciado foi relacionado aos ciúmes, sendo descrito por quase $27 \%$ da população pesquisada. O desemprego também foi referido, aparecendo em 7,5\% dos entrevistados. Sabemos que as questões de gênero configuram o pano de fundo na produção da violência doméstica contra mulheres, entretanto, esses dados apontam também para questões sócio-econômicas e psicológicas envolvidas na perpetuação do problema. Apesar de ser mais citada em extratos

№: 23-24 Ano: 13 jul/ago/set/out/nov/dez 2011 
sociais de menor poder aquisitivo, de forma alguma é intento aqui condicionar a associação do fenômeno violência com más condições sócio-econômicas. A violência também se manifesta em pessoas com melhores condições de renda, acesso e grau de instrução.

E esse fato fica evidente com as perguntas seguintes do formulário. Aproximadamente $70 \%$ do universo estudado conhece alguma mulher que é ou já foi vítima de violência doméstica. Cerca de $10 \%$ da comunidade universitária admitiu que é ou já foi vítima de violência doméstica. E talvez o dado mais surpreendente é que 1,4\% da comunidade universitária (o que corresponde a 5 indivíduos) assumiu que já praticou algum ato de violência doméstica contra mulher. Esse fato merece especial realce, pois, se para um ambiente acadêmico, onde frequentemente as pessoas têm mais acesso à educação/informação o índice é este, questiona-se como será o número nos locais onde não há esse acesso. Como dados adicionais, a pesquisa ainda revelou que $90 \%$ não conhecem sequer algum lugar no litoral do Paraná que ofereça alguma forma de atendimento às mulheres vítimas de violência.

Com base nessa pesquisa de mapeamento realizada inicialmente, foi possível definir alguns desafios e estratégias a serem alcançados durante a execução do projeto subsequente. A primeira ação proposta foi a de sensibilizar a própria comunidade universitária a respeito do tema, tendo visto os resultados da pesquisa. Para isso foram organizadas atividades específicas a esse público. A primeira foi uma sensibilização de combate à violência doméstica contra mulheres que ocorreu no dia Internacional da Mulher. Tal atividade constou de abordagem "corpo a corpo" realizada pelos estagiários do projeto com os membros da instituição e exibição de pôsteres confeccionados pelos estagiários nos corredores da universidade, salientando a importância das mulheres na sociedade e com cenas relativas à violência contra mulheres. Houve também uma projeção sobre a trajetória de Maria da Penha Maia Fernandes, a quem devemos (não somente, mas inclusive) a alcunha da Lei 11.340/06, de 07 de agosto de 2006, batizada de "Lei Maria da Penha" e que versa especificamente sobre violência contra mulheres. Juntamente com a exibição foi veiculada a música "Maria da Penha", homenagem da cantora Alcione à Maria da Penha. E por ser o Dia da Mulher, as mulheres receberam marcadores de página alusivos à data comemorativa, confeccionados artesanalmente pelo grupo. Enquanto isso, o público em geral recebeu folders sobre informações e programas de combate à violência doméstica contra mulheres.

Outra estratégia foi a realização de Oficinas sobre Violência e Cidadania, em espaço curricular de aprendizagem da instituição. Tal espaço é destinado à realização de atividades semanais, que ocorrem todas as quartas-feiras, com duração de 4 horas e com participação de estudantes de todos os cursos, que podem optar dentro de um cardápio de atividades, por aquela que mais lhe desperta o interesse. Surpreendentemente, com abertura inicial de 30 vagas, mais de 40 participantes se inscreveram, demonstrando que esse tema suscita grande interesse pela comunidade universitária.

Paralelamente a essa atividade realizada no campus, por meio do projeto, foi também realizado o mapeamento de pessoas e instituições nos municípios da região, que já atuavam na diminuição da violência doméstica contra mulheres. Assim, foram feitas dezenas de reuniões e visitas contatando pessoas dos mais diversos setores: prefeitos, secretários municipais (de educação, saúde e ação social), profissionais da educação, profissionais da saúde, profissionais da área de assistência social, profissionais da área de segurança pública (como delegados, juízes, oficiais da polícia militar e civil, conselho tutelar, guarda municipal

№: 23-24 Ano: 13 jul/ago/set/out/nov/dez 2011 
e corpo de bombeiros), associações comunitárias e organizações não-governamentais. Em alguns dos locais, apesar de as pessoas estarem cientes do problema, não se encontravam diretamente envolvidas com a questão. Nesse caso, era levado material informativo e eram conclamados à participação nas atividades do projeto.

Dessa forma, foi possível congregar diferentes atores sociais, na perspectiva de formação e consolidação de uma rede intersetorial de enfrentamento à violência doméstica contra mulheres no litoral do Paraná. Nesse sentido, foi também confeccionada uma página na internet[9] com as informações e contatos de todos os participantes da rede, para que os contatos pudessem ser divulgados e que a rede se consolidasse também no ambiente virtual.

Foi realizado ainda o " $1^{\circ}$ Encontro de Combate à Violência Doméstica Contra Mulheres do Litoral Paranaense", em novembro de 2008. O evento contou com a participação de diversos membros da rede que vinha sendo articulada, o que foi de extrema importância, pois muitas vezes os representantes de uma determinada secretaria de um município não dialogam com representantes de outras secretarias e muito menos com representantes de outros municípios. Assim, o momento foi de grande debate, intercâmbio e trocas de experiências, num âmbito intersetorial. Durante o evento foi redigido um documento construído coletivamente, batizado de "Carta Atlântica", onde os presentes fizeram a pactuação de trabalharem numa série de objetivos e estratégias a serem desenvolvidas em conjunto, visando a diminuição da violência doméstica contra mulheres na região.

Apesar de o projeto demonstrar muitos resultados positivos, ele possuía um início e uma previsão de fim. Entretanto, como o fim da violência de gênero ainda encontra-se longe de seu fim definitivo, o tema continuou rendendo frutos. Um deles vem sendo a realização de minha tese de doutorado na área, que tem como proposta aprofundar o estudo nesse campo, buscando (re)conhecer e refletir acerca das relações que se estabelecem entre profissionais de saúde do Sistema Único de Saúde (SUS) do município de Matinhos (PR) e mulheres vítimas de violência doméstica. Essa modalidade de violência de gênero atinge diretamente a saúde e o bem-estar das mulheres, que em decorrência de uma rotina violenta, procuram de maneira recorrente os serviços públicos de saúde. Políticas e práticas específicas de tratamento dessa questão nos serviços de saúde ainda são incipientes. Muitas vezes, os (as) profissionais não sabem como lidar com a questão ou até mesmo não a percebem, como evidenciam importantes estudos desenvolvidos pelas pesquisadoras brasileiras Lilia Blima Schraiber e Ana Flávia Pires Lucas D’Oliveira (2003); Eleonora Menicucci de Oliveira (2007; et al., 2005); e Lia Zanotta Machado (2003).

Essas mulheres aportam no sistema de saúde, na maioria das vezes, sentindo-se bastante frágeis e desamparadas. Nesses locais, por diferentes razões, nem sempre relatam a verdadeira causa de seus agravos. E por outro lado nem sempre os (as) profissionais de saúde relacionam essas injúrias à violência doméstica. Frequentemente essas mulheres são conhecidas pelos (as) profissionais como "poliqueixosas", dada a diversidade de sinais e sintomas físicos e psicológicos, muitas vezes difíceis de serem localizados, explicados, diagnosticados e tratados. São mais suscetíveis a uma série de agravos, como dores crônicas, doenças pélvicas inflamatórias, gravidez indesejada, aborto espontâneo, depressão e comportamentos obsessivo-compulsivos. Esse conjunto de manifestações tem sido descrita por McCauley et al. (1995) como battering syndrome que pode ser traduzida como "síndrome da mulher espancada".

№: 23-24 Ano: 13 jul/ago/set/out/nov/dez 2011 
Tendo em vista essa conjuntura, caracterizada por mulheres fragilizadas que necessitam de um acolhimento em saúde, e por profissionais de saúde que precisam atender mulheres que são vítimas de violência doméstica, pretendo com esse trabalho entender um pouco de que maneira se dá interação entre esses dois atores sociais no âmbito da atenção básica à saúde. Almejo estudar como é a abordagem de profissionais de saúde às mulheres em situação de violência doméstica, investigando se a situação de violência é visibilizada pelos (as) profissionais, mesmo quando não relatada pelas mulheres, bem como se esses (as) consideram a violência um problema de saúde, pertinente à sua área de atuação. Quais os encaminhamentos dados às mulheres em situação de violência doméstica, buscando desenhar o "itinerário da violência". E ainda, ao serem identificados, estes casos são notificados? Esses são apenas alguns dos questionamentos que movem a proposta, buscando evidenciar se a abordagem dos (as) profissionais de saúde a estas mulheres segue um atendimento baseado no modelo biomédico de atenção à saúde, centrado no tecnicismo, no especialismo, na figura do médico e na(s) queixa(s)/patologia(s) biológicas decorrente(s) da situação de violência ou se existem estratégias e atitudes de "acolhimento", categoria descrita por Merhy et al. (1994) e Camargo Júnior et al., (2008), preconizada pela Política Nacional de Humanização em Saúde (2006) do Ministério da Saúde, abordagem de caráter interdisciplinar centrada no indivíduo, vendo-o em sua integralidade e não apenas sua queixa orgânica, e caracterizada por receber, escutar, identificar ativamente riscos e vulnerabilidades e agasalhar, no sentido de dar amparo, em uma atitude de inclusão.

Para cumprir o desígnio dessa pesquisa estão sendo ouvidas as narrativas de interlocutores que atuam nos serviços de atenção primária à saúde e exercem suas atividades na sede de uma Unidade Básica de Saúde (UBS) ou em atividades do Programa de Saúde da Família (PSF) vinculado à Unidade. Essa etapa de pesquisa de campo encontra-se em andamento e estão sendo entrevistadas, diferentes categorias de profissionais de saúde, como fisioterapeutas, enfermeiras (os) e agentes comunitários de saúde. Tal delimitação se deve ao característico estabelecimento de vínculo entre esses profissionais de saúde e as mulheres. Algumas mulheres vítimas de violência também estão sendo ouvidas, buscando estudar a questão em uma via de mão dupla.

Os resultados desse estudo, somados às etapas dos trabalhos anteriores vem fornecendo importantes subsídios que podem (re) orientar políticas públicas tanto na prevenção e assistência do problema, quanto na formação e educação permanente.

\section{CONSIDERAÇÕES FINAIS}

É de grande significância realizar aqui apenas algumas considerações finais a respeito deste artigo, embora jamais concluí-lo. Afinal, se o concluir, decretaria um fim a um trabalho que continua sendo realizado na área de violência de gênero. E esta não se constitui em intenção, até porque ainda está longe de alcançar seu objetivo final, que é a promoção da equidade de gênero na região litorânea do Paraná.

Com a realização deste artigo, foi possível observar, especialmente com base nos dados do mapeamento dessas duas manifestações de violência de gênero, que tanto mulheres quanto homossexuais, bissexuais e transgêneros são notadamente vitimizados nessa região.

№: 23-24 Ano: 13 jul/ago/set/out/nov/dez 2011 
Como reflexão final é importante atentar que atuar na luta pela promoção da equidade de gênero e especialmente na redução das violências, são tarefas bastante complexas. Requerem o diálogo entre diferentes áreas do conhecimento, como ciências humanas, ciências da saúde, ciências da educação, e o envolvimento de distintos setores da sociedade, como educação, saúde, segurança pública, direitos humanos, entre outros. As diferentes manifestações de violências podem repercutir diretamente - e indiretamente também - na qualidade de vida das pessoas. Tentou-se chamar atenção com este trabalho, para duas modalidades específicas de violência de gênero, que são a violência contra homossexuais e a violência doméstica contra mulheres, bem como para a necessidade de articulação de ações intersetoriais para a minimização de tais manifestações.

Por meio de pesquisas quantitativas e qualitativas, foi possível desenhar um pouco do cenário regional em relação a essas duas problemáticas, que se mostram não somente presentes, mas arraigadas em grande parte da população e talvez até na cultura do litoral paranaense. Embora não sejam novidades, se fazendo presentes ao longo da história da humanidade, são muitas vezes banalizadas e até mesmo naturalizadas, mesmo nos dias atuais, estando ainda longe de seu fim definitivo. Deve-se acreditar entretanto, que apesar de estarem longe de seu fim, essas manifestações de violência de gênero podem e devem ser combatidas com a combinação de estratégias pontuais, progressivas e permanentes, cabendo a cada ser humano a sua participação e aderência à causa.

Por meio deste ensaio, tentei ilustrar um pouco algumas das ações que venho desenvolvendo nesse sentido na realidade onde vivo. É de extrema importância realçar, que não venho realizando todo esse trabalho sozinho. É um trabalho coletivo, que teve início no seio do grupo REGEDI e que merece, mesmo que de maneira singela os sinceros agradecimentos aos parceiros deste grupo, assim como do grupo GETEC/UTFPR por me iluminarem nesse caminho.

\section{NOTAS}

[1] Fisioterapeuta (FURB), Mestre em Fisiologia (UFPR), Doutorando em Saúde Coletiva - Área de Ciências Humanas em Saúde (UNIFESP). Professor Assistente, Universidade Federal do Paraná - Setor Litoral. e-mail:

sarcosina@yahoo.com.br

[2] Para mais detalhes, ver pesquisas recentes realizadas em parceria com a Organização Mundial da Saúde por GarciaMoreno et al. 2006 e Schraiber e D'Oliveira, 2002.

[3] A homofobia é uma categoria descrita como conjunto de atitudes negativas em relação aos homossexuais, somados ao medo de tornar-se homossexual ou tomar gosto pela experiência homossexual. No caso do homem, ele teme ser suspeito de ser homossexual, reagindo com pânico, hostilidade e até violência contra os homossexuais, tentando manter um estereótipo "macho" (VIEIRA, 1996). Atualmente o movimento LGBT (lésbicas, gays, bissexuais, travestis e transexuais) também criou as alcunhas lesbofobia, bifobia e transfobia, se referindo especificamente aos casos de violências contra lésbicas, violência contra bissexuais e violência contra transgêneros, respectivamente. Assim, tornou-se comum tanto o uso isolado de cada categoria, bem como somente a categoria homofobia, ficando subentendida a lesbofobia, a bifobia e a transfobia, ou ainda a alcunha "homo/lesbo/bi/transfobia". Nesse trabalho será adotada a categoria homofobia, incluindo aí todos esses desdobramentos.

[4] O projeto foi realizado numa parceria entre GETEC/UTFPR (Grupo de Estudos de Gênero e Tecnologia da Universidade Tecnológica Federal do Paraná), REGEDI/UFPR (Grupo Interdisciplinar de Estudos, Ensino-Pesquisa-Extensão em Representações de Gênero e Diversidade da Universidade Federal do Paraná) e Secretaria Municipal de Educação e Cultura de Matinhos, com apoio do Ministério da Educação. Para mais detalhes, ler Carvalho e Casagrande (2008).

№: 23-24 Ano: 13 jul/ago/set/out/nov/dez 2011 
[5] O projeto intitulado "Mapeamento e estabelecimento de redes de conscientização e defesa dos direitos das mulheres no combate à violência doméstica nos municípios do litoral do Paraná", realizado no biênio 2007-2009, teve o apoio da SETI - Secretaria de Estado da Ciência, Tecnologia e Ensino Superior do Paraná. Para detalhes adicionais do projeto, inclusive a relação dos membros participantes, objetivos, e contatos, pode ser acessada a página do projeto no endereço http:// www.litoral.ufpr.br/regedi/regedidireitoshumanos/

[6] A comunidade universitária total em março de 2008 era estimada em cerca de 550 pessoas, sendo 75 docentes, 25 funcionários e 450 discentes. Tal número foi repassado pela Unidade de Gestão Acadêmica, porém é de difícil precisão, pois apesar de muitos estudantes terem matrícula ativa nos cursos, muitas vezes não frequentam as aulas, sendo considerados desistentes. Por isso salientamos que obter a aderência de 364 participantes foi considerado um universo bastante significativo.

[7] Hartmann (1979) define patriarcado como um conjunto de relações sociais que tem uma base material e no qual há relações entre homens, e solidariedade entre eles, que os habilitam a controlar as mulheres. Patriarcadoé, pois, o sistema masculino de opressão das mulheres.

[8] O grifo é do autor, para realçar a idéia de posse que o patriarcado denota.

[9] www.litoral.ufpr.br/regedi/regedidireitoshumanos

\section{REFERÊNCIAS BIBLIOGRÁFICAS}

ABRAMOVAY, M.; CASTRO, M. G.; SILVA, L. B. Juventudes e sexualidade. Brasília: UNESCO Brasil, 2004. ADEODATO, V. G.; CARVALHO, R. R.; SIQUEIRA, V. R.; SOUZA, F. G. M. Qualidade de vida e depressão em mulheres vítimas de seus parceiros. Revista de Saúde Pública, São Paulo, v. 39, n. 1, p. 108-113, fev. 2005.

BEAUVOIR, S. O Segundo Sexo. Rio de Janeiro: Nova Fronteira, 1980.

BRASIL. Decreto-lei n. 11.340, de 7 de agosto de 2006. Disponível em <http://www.planalto.gov.br/ccivil/_Ato20042006/2006/Lei/L11340.htm>, acesso em 28/07/2007

BRASIL SEM HOMOFOBIA: Programa de Combate à Violência e à Discriminação contra GLBT e Promoção da Cidadania Homossexual. Brasília: Secretaria Especial de Direitos Humanos, 2004.

BRASIL. Ministério da Saúde. Secretaria de Atenção à Saúde. Núcleo Técnico da Política Nacional de Humanização.

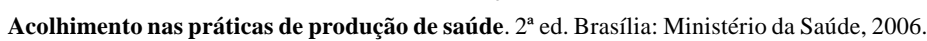

BOURDIEU, P. A Dominação Masculina. Rio de Janeiro: Bertrand Brasil, 1999.

BUTLER, J. Problemas de gênero: feminismo e subversão da identidade. $2^{\mathrm{a}}$ ed. Rio de Janeiro: Civilização Brasileira, 2008.

CAMARGO JÚNIOR, K. R.; et al. Avaliação da atenção básica pela ótica político-institucional e da organização da atenção com ênfase na integralidade. Cadernos de Saúde Pública, Rio de Janeiro, n. 24, sup 1, p. S58-S68, 2008.

CARVALHO, M. G.; CASAGRANDE, L. S. Gênero e diversidade sexual no espaço escolar: temáticas que necessitam ser abordadas. Cadernos de Gênero e Tecnologia, Curitiba, n.14, ano 04, p. 9-24, abr/jun. 2008.

DA MATTA, R. As raízes da violência no Brasil. In: PAOLI, M. C.; BENEVIDES, M. V.; PINHEIRO, P. S.; DA

MATTA, R. A violência brasileira. São Paulo: Brasiliense, 1982.

FRIEDAN, B. Mística Feminina. Petrópolis: Vozes, 1971.

GARCIA-MORENO; C.; JANSEN, H. A. F. M.; ELLSBERG, M.; HEISE, L.; WATTS, C. H. (On behalf of the WHO multi-country study on women's health and domestic violence against women study team). Prevalence of intimate partner violence: findings from the WHO multi-country study on women's health and domestic violence. The Lancet, v. 368, n. 7, p. 1260-9, oct. 2006.

HARTMANN, H. Capitalism, patriarchy and job segregation by sex. In: JACKSON, S.; SCOTT, S. Gender: a sociological reader. London: Routledge, 2002.

JORDÃO, F. P. Percepções e reações da sociedade sobre a violência contra a mulher - Análise de pesquisa. São

No: 23-24 Ano: 13 jul/ago/set/out/nov/dez 2011 
Paulo: Instituto Patrícia Galvão, 2006.

LAQUEUR, T. Inventando o Sexo: corpo e gênero dos gregos a Freud. Rio de Janeiro: Relume Dumará, 2001.

LOURO, G. L. O corpo educado: pedagogias da sexualidade. $2^{\text {a }}$ ed. Belo Horizonte: Autêntica, 2000.

MACHADO, L. Z. Entre o inferno e o paraíso: saúde, direitos e conflitualidades. Série Antropologia UNB. Brasília, 2003. Disponível em <http://www.unb.br/ics/dan/ Serie342empdf.pdf>, acesso em 27/10/2008.

MACHADO, L. Z. Matar e morrer no feminino e no masculino. Série Antropologia UNB. Brasília, 1998. Disponível em <http://www.unb.br/ics/dan/Serie239empdf.pdf>, acesso em 27/10/2008.

MCCAULEY, J.; KERN, D. E.; KOLODNER, K.; DILL, L.; SCHROEDER, A. F.; DECHANT, H. K.; RYDEN, J.; BASS, E. B.; DEROGATIS, L. R. The "Battering Syndrome": Prevalence and Clinical Characteristics of Domestic Violence in Primary Care Internal Medicine Practices. Annals of Internal Medicine, v. 123, n. 10, p. 737-746, nov. 1995.

MERHY, E. E.; CAMPOS, G. W. S. \& CECÍLIO, L. C. O. (Org.). Inventando a Mudança na Saúde. São Paulo: Hucitec, 1994

NICHOLSON, L. Interpretando o gênero. Revista Estudos Feministas, Florianópolis, v. 8, n. 2, p. 9-41, 2000.

OLIVEIRA, E. M. Fórum: violência sexual e saúde. Cadernos de Saúde Pública, Rio de Janeiro, v. 23, n. 2, p. $455-$ 458, fev. 2007.

OLIVEIRA, E. M.; BARBOSA, R. M.; MOURA, A. A. V. M.; KOSSEL, K.; MORELLI, K.; BOTELHO, L. F. F.; STOIANOV, M. Atendimento às mulheres vítimas de violência sexual: um estudo qualitativo. Revista de Saúde Pública, São Paulo, v. 39, n. 3, p. 376-82, 2005.

OLIVEIRA, S. Nem homem gosta de bater, nem mulher de apanhar: fortalecendo a rede de proteção. In: CASTILLOMARTÍN, M. \& OLIVEIRA, S. Marcadas a Ferro, violência contra mulher: uma visão multidisciplinar. Brasília: Presidência da República/ SEPM, 2005. p. 234-238.

PEDRO, J. M. Traduzindo o debate: o uso da categoria gênero na pesquisa histórica. História, São Paulo, v. 24, n. 1, p. 77-98, 2005.

PINKER, S. Como a mente funciona. São Paulo: Companhia das Letras, 1999.

SAFFIOTI, H. I. B. Gênero e patriarcado: a necessidade da violência. In: CASTILLO-MARTÍN, M. \& OLIVEIRA, S. Marcadas a Ferro, violência contra mulher: uma visão multidisciplinar. Brasília: Presidência da República/SEPM, 2005. p. 35-76.

SCHRAIBER, L. B.; D'OLIVEIRA, A. F. P. L. O que devem saber os profissionais de saúde para promover os direitos das mulheres em situação de violência doméstica. 2.ed. São Paulo: Coletivo Feminista Sexualidade e Saúde, 2003. Disponível em: <http://www. mulheres.org.br/violencia/documentos/cartilha_violencia.pdf>. Acesso em: 14/04/ 2008.

SCHRAIBER, L.; D'OLIVEIRA, A. F. P. L. World health organization multi country study on women's health and domestic's violence against women in Brazil. São Paulo: Relatório Preliminar de Pesquisa, 2002. Mimeo.

SCOTT, J. Gênero: uma categoria útil para a análise histórica. Recife: SOS Corpo, 1996.

SCHIEBINGER, Londa. O feminismo mudou a ciência? Bauru, SP: EDUSC, 2001.

STOLLER, R. J. Sex and gender. New York: Science House; London: Hogarth Press and Institute of Psychoanalysis. 1968.

SUÁREZ, M.; BANDEIRA, L. (Org.). Violência, Gênero e Crime no Distrito Federal. Brasília: Paralelo 15, 1999. VIEIRA, T. R. Mudança de sexo - aspectos médicos, psicológicos e jurídicos. São Paulo: Santos, 1996.

VILLAGÓMEZ, E. Los costes econômicos y sociales de la violencia contr la mujer en Andalucía, España. In: CASTILLOMARTÍN, M. \& OLIVEIRA, S. Marcadas a Ferro: violência contra mulher - uma visão multidisciplinar. Brasília: Presidência da República / Secretaria Especial de Políticas para as Mulheres, 2005. p. 192-198.

WAISELFISZ, J. J. Mapa da violência dos municípios brasileiros - 2008. Brasília: Ministério da Saúde/Ministério da Justiça, 2008.

№: 23-24 Ano: 13 jul/ago/set/out/nov/dez 2011 